\title{
The staged roll-out of an MRSA intervention bundle in Signapore featuring universal active surveillance
}

\author{
D Fisher ${ }^{*}$, R Lin, LY Hsu, O Kooi Li, TM Ng, P Tambyah \\ From International Conference on Prevention \& Infection Control (ICPIC 2011) \\ Geneva, Switzerland. 29 June - 2 July 2011
}

\section{Introduction / objectives}

Between 2004 and 2006, Singapore's 997 bed National University Hospital (NUH) had 62 hospital acquired MRSA bacteraemias/year. Another 200 inpatients/year had new non blood borne MRSA infections. Minimal active surveillance was undertaken.

\section{Methods}

Between 2006 and 2010, universal active surveillance (on admission and discharge), isolation/cohorting, data feedback loops and standardised hand hygiene $(\mathrm{HH})$ audits were rolled out in a stepwise fashion across NUH. A comprehensive hand hygiene programme was institutionalised. MRSA acquisition was defined as having a positive exit swab yet negative entry and no known previous MRSA. Ward specific $\mathrm{HH}$ compliance and acquisition rates were fed back via public displays on each ward monthly.

\section{Results}

All adult medical and surgical wards had implemented the bundle by July 2010 . In that month 3620 entry swabs were taken. Compliance rates with exit swabs are $>85 \%$. MRSA acquisition fell from 10.1 to $3.1 \%$ and from 9.2 to $2.8 \%$ in our Intensive Care Units and general wards respectively. Nosocomial bacteraemia rates fell from $0.23 / 1000$ pt days in 2008 to 0.11 in 2010 . The MRSA burden however remains high hospital wide and vancomycin use has not fallen.

\section{Conclusion}

The value of active surveillance remains controversial and near impossible to prove in a real life setting in the short term. A major reservoir continues to exist at

National University Hospital, Singapore, Singapore
NUH. A high baseline transmission rate may represent the initial identification of the reservoir of MRSA using an imperfect screening tool. Genuine success can only be acknowledged with a fall in infection rates, the total burden plus antibiotic useage. Acquisition rates are a useful interim tool but healthy scepticism is required during the collection of early data during major MRSA prevention programmes.

\section{Disclosure of interest}

None declared.

Published: 29 June 2011

doi:10.1186/1753-6561-5-S6-084

Cite this article as: Fisher et al:: The staged roll-out of an MRSA

intervention bundle in Signapore featuring universal active surveillance. BMC Proceedings 2011 5(Suppl 6):O84.

Submit your next manuscript to BioMed Central and take full advantage of:

- Convenient online submission

- Thorough peer review

- No space constraints or color figure charges

- Immediate publication on acceptance

- Inclusion in PubMed, CAS, Scopus and Google Scholar

- Research which is freely available for redistribution 